\title{
Connecting water science and policy in India: lessons from a systematic water governance assessment in the city of Ahmedabad
}

\author{
Martien Aartsen ${ }^{1,2} \cdot$ Stef Koop $^{1,3} \cdot$ Dries Hegger $^{1}$ (D) $\cdot$ Bijoy Goswami $^{4} \cdot$ Johan Oost $^{5} \cdot$ Kees Van Leeuwen ${ }^{1,3}$
}

Received: 5 April 2017 / Accepted: 24 May 2018 / Published online: 7 June 2018

(C) The Author(s) 2018

\begin{abstract}
Cities in the Global South are facing high climate vulnerabilities. Still, systematic insights in factors that stimulate or impede governance capacity are less widely available than those in the Global North. Moreover, translating relevant scientific insights into policy and practice is often problematic. Hence, there is a need for feasible interactive approaches that may facilitate integration between science and policy. In this paper, we assess to what extent the City Blueprint Approach may facilitate such meaningful science-policy interaction. This approach has been developed in the context of Watershare and the European Innovation Partnership on Water. We discuss the content of the approach and reflect on the process of applying it in the case of Ahmedabad, India. First, we carried out an overall assessment of Ahmedabad's trends, pressures, and integrated water resources management. Important challenges of Ahmedabad are water pollution, water scarcity (decline of groundwater levels), heat risk and urbanisation. Second, a governance capacity assessment provided a clearer understanding of the main enabling and limiting conditions that determine the city's ability to govern these challenges. It was found that the governance conditions regarding learning, stakeholder engagement and implementing capacity are most in need of improvement. Next, we zoomed in on a specific development in which these limiting governance conditions were better developed: Ahmedabad's Heat Action Plan. Based on our results and experiences, we reflect on the generalisability of the findings on the City Blueprint Approach (CBA)'s usefulness for improving science-policy interactions and water governance to India as well as the Global South more generally.
\end{abstract}

Keywords City Blueprint Approach - Science-policy interface - Governance capacity - Water governance - Smart cities, climate change adaptation

Editor:Marc Metzger

Electronic supplementary material The online version of this article (https://doi.org/10.1007/s10113-018-1363-1) contains supplementary material, which is available to authorized users.

Dries Hegger

d.1.t.hegger@uu.nl

Martien Aartsen

Martienaartsen@gmail.com

Stef Koop

stef.koop@kwrwater.nl

Bijoy Goswami

bijoy.goswami@ceeindia.org

Johan Oost

johan.oost@wetskills.com

Kees Van Leeuwen

kees.van.leeuwen@kwrwater.nl
1 Environmental Governance, Copernicus Institute of Sustainable Development, Utrecht University, VeningMeineszgebouw A, Princetonlaan 8a, 3584 CB Utrecht, The Netherlands

2 Twynstra Gudde, Stationsplein 1, 3818 LE Amersfoort, The Netherlands

3 KWR Watercycle Research Institute, Groningenhaven 7, 3430 BB Nieuwegein, The Netherlands

4 Centre for Environment Education Ahmedabad, Thaltej Tekra, Ahmedabad 380054, India

5 Wetskills Foundation, Binckhorstlaan 36-M420, 2516 BE The Hague, The Netherlands 


\section{Introduction}

Today, cities are home to $54 \%$ of the world's population. By 2050, this number will rise to $66 \%$ (UN Habitat 2016). The adverse impacts of inadequate maintenance of urban water and wastewater infrastructures and poor solid waste management, both amplified by rapid urbanisation and climate change, may lead to flooding, water scarcity and pollution that can overwhelm the adaptive capacity of cities (Koop and Van Leeuwen 2017). Indian cities are home to an estimated 340 million people, or $30 \%$ of the population. These cities will become more important as by 2030 , an estimated 590 million people, or $40 \%$ of the population are projected to be living in cities. In a global context, the urban expansion in India will be immense. By 2030, India will have 68 cities with more than 1 million inhabitants, 13 cities with more than 4 million inhabitants, and 6 megacities with populations of 10 million and more (MGI 2010).

Urbanisation provides both threats and opportunities for water infrastructures. Cities provide many scale benefits. The cost of basic services is 30-50\% cheaper in concentrated population centres than that in rural areas (MGI 2010). However, many of the threats to urban populations in India are water-related: pollution, water-borne diseases, extreme rainfall and changes in river flows, as well as droughts. In addition, coastal regions are faced with sea level rise, increasing cyclone intensity and saltwater intrusion (Surinaidu et al. 2015; Vinke et al. 2016). Urbanisation and industrialisation in combination with inefficiencies in water use are becoming a serious barrier for India's future economic growth and development. A lack of adequate enforcement and monitoring of existing water policies undermine water governance (OECD 2014). Moreover, local governance networks often lack sufficient capacity to implement the strategic goals set by national level institutions (Kumar et al. 2012). The OECD therefore emphasises on strengthening mechanisms and institutions to facilitate vertical (amongst levels of government) and horizontal (amongst sectors) coordination (OECD 2014). Improving water governance capacity might be the key in addressing India's urban water challenges.

Enhancing the water governance capacity in cities is to some extent a science-policy interaction problem. Available knowledge about water systems in cities as well as stimulating and hampering factors for improving water governance capacity is fragmented and sometimes contradictory (e.g. Ostrom 2009; Biesbroek et al. 2013; Plummer et al. 2012; Eisenack et al. 2014); they tend to lack empirical validation (Biesbroek et al. 2013; Van Kersbergen and Van Waarden 2004; Pahl-Wostl 2009) and are therewith often insufficiently tailored to local contexts. This hampers the possibilities to do cumulative research (Cairney 2013) that contributes to a joint knowledge base and enables the drawing of generalisable lessons. Particularly in the field of urban water governance, there is a need for a clear empirical-based frame of reference to overcome knowledge fragmentation and thereby enable meaningful science-policy interaction that can facilitate cities to better govern water-related challenges. Because urban challenges of water, waste and climate change are by nature multidisciplinary and decisions and policy affect many stakeholders, it also requires a comprehensive assessment approach which provides a frame for broad understanding amongst all relevant actors.

The City Blueprint Approach (CBA) has been developed in the context of the Watershare platform and the European Innovation Partnership on Water (European Commission 2017d) to share applied knowledge. This paper reflects on the potential the CBA may have to address the aforementioned problems. In order to do so, we assess features related to its content and to the process through which the approach is applied (Koop and Van Leeuwen 2015a, b). Regarding its content, the CBA is a systematic and standardised urban water governance assessment framework. It consists of three complementary frameworks. First, the Trends and Pressures Framework (TPF) identifies the city's main social, environmental and financial challenges that may affect water management. Second, the City Blueprint performance Framework (CBF) identifies the current state of integrated water management ranging from drinking water, infrastructure, wastewater treatment and climate adaptation to water scarcity, extreme rainfall and urban heat islands. Finally, the Governance Capacity Framework (GCF) analyses the main barriers and opportunities for cities to increase their capacity to govern specific water challenges that require effective collaboration between different institutions. The first two frameworks, the TPF and CBF, have currently been applied in over 70 cities across 35 countries. Detailed studies of the cities of Amsterdam (Van Leeuwen and Sjerps 2015), Hamburg (Van Leeuwen and Bertram 2013), Ho Chi Minh City (Van Leeuwen et al. 2016), Istanbul (Van Leeuwen and Sjerps 2016), Melbourne (Van Leeuwen 2017), New York (Feingold et al. 2017), Rotterdam (Van Leeuwen et al. 2012) and Quito (Schreurs et al. 2018) have been published. Furthermore, the European Commission has recently launched the Urban Water Atlas for Europe-developed around 46 City Blueprint studies - to encourage citizens to take an interest and get involved in water issues through presenting Europe's water challenges in an innovative, accessible and attractive format, combining science and arts (Gawlik et al. 2017).

Second, the paper assesses the potential of the CBA to facilitate joint knowledge production by evaluating the process through which the approach has been implemented (Hegger et al. 2012; Van Enst et al. 2014). It has a standardised procedure which can function as a boundary object that is an object that facilitates discussion between different communities and viewpoints (Star and Griesemer 1989). The CBA also 
has related processes of knowledge integration by researchers in collaboration with stakeholders, which together may constitute an adequate science-policy interface for strengthening water governance capacity in cities. While there are emerging insights into success conditions for joint knowledge production in the context of water governance and climate adaptation in the Global North (Hegger et al. 2012; Raadgever et al. 2012), these insights have not yet been systematically translated to countries in the Global South. In cities in the Global South, water challenges are often more pressing while science-policy interaction dynamics might differ substantially from those in Europe and Northern America (McGranahan et al. 2001). Hence, the merits of the CBA as a means to pursuing joint knowledge production in countries in the Global South such as India have yet to be fully explored.

The current paper intends to address this knowledge gap. We aim to explore the possibilities for the CBA to serve as a productive science-policy interface which can have the potential to enhance water governance capacity, particularly in the context of India. This is done through applying the CBA in the case city of Ahmedabad.

To fulfil the research aim, the following steps will be taken. The 'Methods' section provides a detailed description of the CBA, including an explanation of the associated data collection and analyses. We also provide a short description of the features of the city of Ahmedabad as well as a further justification for its selection. The 'Results' section provides the main content-wise results stemming from the application of the CBA. The 'Discussion' section reflects on the usefulness of the results and reflects on the potential of the CBA to constitute a productive science-policy interface. The 'Conclusion' section concludes the paper.

\section{Methods}

\section{City Blueprint Approach}

The City Blueprint Approach is an action of the European Innovation Partnership on Water (European Commission 2017d) and Watershare (Watershare 2017). The CBA consists of three complementary frameworks: (1) the Trends and Pressure Framework (TPF) to assess the main challenges of cities, (2) the City Blueprint Framework (CBF) to provide an overview of integrated water resources management (IWRM), and (3) the Governance Capacity Framework (GCF) to assess water governance (Fig. 1).

\section{Trends and Pressure Framework}

Each city has its own context-specific challenges. The TPF consists of 12 descriptive indicators that summarise the

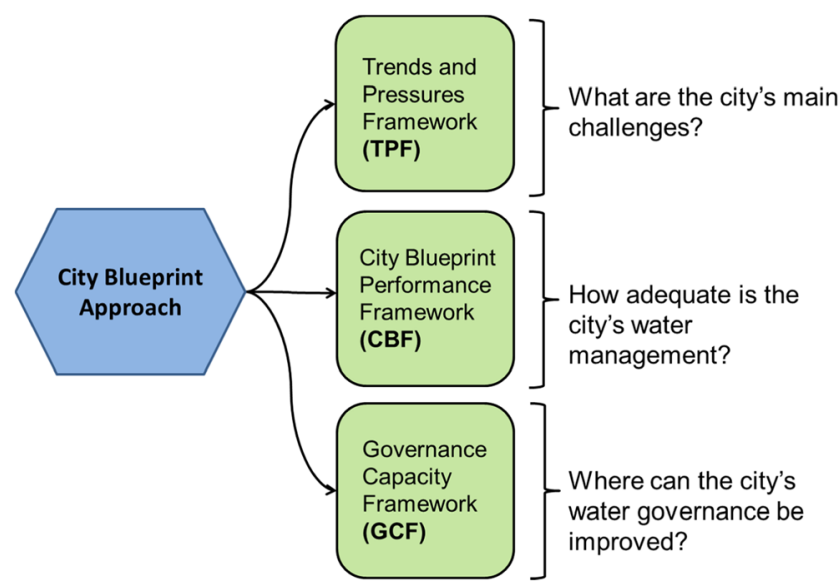

Fig. 1 Overview of the City Blueprint Approach which consist of three separate but complementary assessment frameworks (Koop and Van Leeuwen 2015a, b; Koop et al. 2017)

exogenous social, environmental and financial challenges that can hardly be influenced by the local authorities. Each indicator has been scaled from 0 to 4 points, where a higher score represents a higher urban pressure or concern (Koop and Van Leeuwen 2015a). Details of the methodology and calculation formulas of the TPF indicators are provided at the EIP Water website (European Commission 2017a).

\section{City Blueprint Framework: integrated water resources management}

The CBF consists of 25 performance-oriented indicators divided over seven broad categories that together strive to provide a comprehensive overview of a city's IWRM. The categories are (1) water quality, (2) solid waste treatment, (3) basic water services, (4) wastewater treatment, (5) infrastructure, (6) climate robustness and (7) governance. The latter category includes four indicators, i.e. management and action plans, public participation, water efficiency measures and attractiveness that provide a quick snapshot for cities that do not apply the more extensive GCF. The CBF indicators are scored from 0 to 10 points according to a standardised and reproducible method that has been published (Koop and Van Leeuwen 2015a) and can be found at the EIP website (European Commission 2017b). The output of the CBF is twofold: a spider diagram presenting the indicator scores and the Blue City Index (BCI), which is the geometric mean of the 25 performance indicators. The required data to calculate the TPF and CBF indicators were collected from publicly available sources such as international databases, national and local reports, governmental websites and scientific articles. The data were co-collected together with local stakeholders as they were asked to provide feedback and provide additional information on the preliminary results. 


\section{Water Governance Capacity Framework}

Based on an extensive literature study, Koop et al. (2017) proposed an empirical-based diagnostic framework that provides insights into the main conditions that together determine the governance capacity needed to address urban water challenges. This framework consists of nine governance conditions divided over three dimensions. Each governance condition is split up into three indicators, resulting in 27 governance indicators (Table 1).

Nine conditions are identified, each with three indicators that are scored according to a Likert scale ranging from very encouraging $(++)$ to very limiting $(--)$ to the overall governance capacity to address water-related challenges in cities (Koop et al. 2017).

Table 1 The water Governance Capacity Framework (GCF) consisting of three dimensions: knowing, wanting and enabling

\begin{tabular}{|c|c|c|}
\hline Dimensions & Conditions & Indicators \\
\hline \multirow[t]{9}{*}{ Knowing } & \multirow[t]{3}{*}{1 Awareness } & 1.1 Community knowledge \\
\hline & & 1.2 Local sense of urgency \\
\hline & & 1.3 Behavioural internalisation \\
\hline & \multirow[t]{3}{*}{2 Useful knowledge } & 2.1 Information availability \\
\hline & & 2.2 Information transparency \\
\hline & & 2.3 Knowledge cohesion \\
\hline & \multirow[t]{3}{*}{3 Continuous learning } & 3.1 Smart monitoring \\
\hline & & 3.2 Evaluation \\
\hline & & 3.3 Cross-stakeholder learning \\
\hline \multirow[t]{9}{*}{ Wanting } & \multirow{3}{*}{$\begin{array}{l}4 \text { Stakeholder engagement } \\
\text { process }\end{array}$} & 4.1 Stakeholder inclusiveness \\
\hline & & 4.2 Protection of core values \\
\hline & & $\begin{array}{l}4.3 \text { Progress and variety of } \\
\text { options }\end{array}$ \\
\hline & \multirow[t]{3}{*}{5 Management ambition } & $\begin{array}{l}\text { 5.1 Ambitious and realistic } \\
\text { management }\end{array}$ \\
\hline & & 5.2 Discourse embedding \\
\hline & & 5.3 Management cohesion \\
\hline & \multirow[t]{3}{*}{6 Agents of change } & 6.1 Entrepreneurial agents \\
\hline & & 6.2 Collaborative agents \\
\hline & & 6.3 Visionary agents \\
\hline \multirow[t]{9}{*}{ Enabling } & \multirow{3}{*}{$\begin{array}{l}7 \text { Multi-level network } \\
\text { potential }\end{array}$} & 7.1 Room to manoeuvre \\
\hline & & $\begin{array}{l}\text { 7.2 Clear division of } \\
\text { responsibilities }\end{array}$ \\
\hline & & 7.3 Authority \\
\hline & \multirow[t]{3}{*}{8 Financial viability } & 8.1 Affordability \\
\hline & & $\begin{array}{l}8.2 \text { Consumer willingness to } \\
\text { pay }\end{array}$ \\
\hline & & 8.3 Financial continuation \\
\hline & \multirow[t]{3}{*}{9 Implementing capacity } & 9.1 Policy instruments \\
\hline & & 9.2 Statutory compliance \\
\hline & & 9.3 Preparedness \\
\hline
\end{tabular}

The GCF separately analyses five water-related governance challenges: (1) flood risk, (2) water scarcity, (3) urban heat islands, (4) wastewater treatment and (5) solid waste treatment. These challenges were selected because they are important consequences of the reinforcing impacts of urbanisation and climate change, and projected to grow in importance in the near future. Each of the 27 indicators has its own pre-defined question that needed to be answered during the analysis. The indicators were scored according to an indicatorspecific Likert scale that ranges from very encouraging $(++)$ to very limiting $(--)$ to the overall governance capacity. By providing arguments and references, the indicator scores were substantiated. In order to obtain the necessary data to score the indicators, a triangular approach has been applied to validate findings by different sources. This triangular approach consists of three consecutive steps:

1. A desk study of scientific literature, grey literature and official government sources, resulting in a substantiated preliminary scoring of the indicators.

2. A thorough investigation to identify stakeholders, categorise them and define their responsibilities, relations and interactions (Reed et al. 2009). The importance/influence matrix was used (DFID 2003) to provide this insight and select a range of stakeholders with the broadest variety in interests in order to ensure an inclusive knowledge coproduction process. Importance refers to the priority given by the stakeholder. Influence refers to the power a stakeholder has to facilitate or impede the achievement of an activity, plan or objective. This matrix has four classes: (1) crowd (low importance and low influence), (2) context (low importance and high influence), (3) subjects (high importance and low influence) and (4) key players (high importance and high influence). For all these four classes, at least one stakeholder representing the government, the market and civil society was selected (as suggested, e.g. by Lange et al. 2013). The stakeholder analysis was done by the researchers and verified by the Centre for Environment Education in Ahmedabad. The selected stakeholders included multiple government departments of Ahmedabad's Municipal Corporation and Gujarat State government, Gujarat Pollution Control Board and the Gujarat Water Supply and Sewerage Board. Respondents from Gujarat University and CEPT University provided inputs from an academic perspective. A wastewater service company and the Public Health Foundation of India (PHFI) are private and publicprivate bodies that deal on a daily basis with public services. A journalist from the Times of India was included in the selection to reflect on the urban equity and public water services. The selection furthermore included three NGOs involved in public water services, capacity building and urban poor (amongst other causes): the Urban 
Management Centre Group, Paryavaran Mitra, Mahila Housing SEWA Trust (MHT), and VIKSAT, a Nehru Foundation Institution. Lastly, several key sites in Ahmedabad have been visited in collaboration with a network of concerned citizens to verify gathered information in the local context and to interact with residents. Often, multiple persons representing the identified key stakeholders were selected for semi-structured interviews with the aim of gathering the relevant information to score the indicators but also to allow for follow-up questions for clarification or to better understand the content. Diversity amongst the interviewees was assured by selecting respondents from organisations with different roles, expertise and responsibilities in order to decrease the risk of bias and unravel socially desirable responses. Moreover, the indicators were scored for each individual interview in order to minimise a data interpretation bias. The scores were determined based on all these separate scorings and additional collection of reliable and accessible information that may ratify or provides nuance to the interview findings. In total, 17 interviews were conducted during a 5-week period.

3. Finally, the overall results have been checked by asking all the 17 interviewees to provide feedback in the form of additional information, arguments etc. After incorporating the received feedback, the final scores were determined.

This three-step approach has enabled a high degree of reproducibility and allowed for a basic comparison between water challenges within a city and between cities. The indicator's pre-defined questions and Likert scale are publicly accessible (European Commission 2017c) and explained in detail by Koop et al. (2017). Moreover, the raw indicator score justifications for the city of Ahmedabad are made available as supplementary material. At present, the GCF analysis has also been published for the city of Quito (Ecuador; Schreurs et al. 2018), New York City (USA; Feingold et al. 2017) and Amsterdam (the Netherlands; Koop et al. 2017).

\section{Case study: Ahmedabad (India)}

To study India's urban water governance, the city of Ahmedabad is chosen as a case study. Ahmedabad is the biggest city of the Gujarat state. The city is situated in a tropic monsoon region with a high chance of drought and heat waves during the dry season, and water nuisance during the monsoon (Gupte 2011). The city's strategy to reduce the impact of heat waves is an interesting case that might provide lessons for other water challenges in the city but also to other cities in India. In terms of water availability, the Sabarmati River primarily supplies the city with water during the monsoon. Throughout the rest of the year, fresh water is brought down to Ahmedabad by the Narmada canal. Ahmedabad's industries pollute both ground and surface water. As a consequence, the city's rivers and canals are known to be very polluted (Gupte 2011; Maheshwari 2016; Prajapati 2014). The city is in many ways representative for India's large cities. With a population of 7.34 million, Ahmedabad is the seventh largest Indian city. Ahmedabad's 3.3\% urbanisation rate reflects the annual urban growth of India's ten largest cities of $3.0 \%$. These urbanisation rates imply strong urban growth, as such, Ahmedabad is expected to grow with more than 2 million by 2025 (UN Habitat 2016). Ahmedabad's governance situation also shares characteristics with India's largest cities. For example, the Annual Survey of Indian City-Systems (ASICS) scored Ahmedabad's governance quality index 3.2 out of 10 , which is just below the Indian average of 3.4 (Janaagraha Centre for Citizenship and Democracy 2015). The ASICS evaluates the quality of governance in Indian cities based on factors such as urban planning, urban capacities, political representation, transparency, accountability and participation. These statistics make Ahmedabad a suitable case study to explore the main water governance challenges in India's largest cities and in a broader sense representative for other rapidly growing cities.

\section{Results}

\section{Outcomes of trends, pressures and integrated water resources management in Ahmedabad}

The main social, environmental and financial trends and pressures that may hamper Ahmedabad's IWRM are related to heat risk, water scarcity and urbanisation. Heat risk is posing an ever-growing challenge to Ahmedabad's inhabitants, with 2016 reaching record high heat wave temperatures of as high as $48^{\circ} \mathrm{C} .{ }^{1}$ Widespread building projects on the city's outskirts reflect the high urbanisation rate of $3.3 \%$ annually which will put increasing pressure on the city's freshwater resources (UN Habitat 2016). Fresh water is already scarce in this semi-arid region and the projected effects of climate change will further diminish the freshwater availability (Gupte 2011). In particular, unregulated groundwater abstraction through private bore wells is steeply lowering the groundwater table. Although public information is limited, it can be assumed that groundwater levels are declining with several metres per year and, as a consequence, the remaining groundwater reserves are salinizing (Gupte 2011). Moreover, empirical measurements of the river water quality in the vicinity of Ahmedabad indicate that the water quality is moderate to bad (Prajapati 2014; Shah and Joshi 2015).

\footnotetext{
${ }^{1} \mathrm{http}: / /$ www.skymetweather.com/content/weather-news-and-analysis/severeheatwave-in-gujarat-to-persist/
} 
The results of the CBF indicate that Ahmedabad's water management performance is relatively low with an overall BCI of 3.13 points out of a maximum score of 10 (Fig. 2). Overall, Ahmedabad scores relatively high on basic water services (i.e. access to drinking water, access to sanitation and drinking water quality). Nevertheless, there are large disparities across Ahmedabad's inhabitants. A considerable part of the population still lacks access to safe drinking water and sanitation, especially in the slums. Here, the municipal piped water is erratic and only runs a few hours per day. The few connections in the slums are often shared amongst households. Having access to a water connection therefore does not necessarily mean that there is adequate access to water and sanitation. Middle class housing complexes are less dependent on municipal water because they enjoy private bore wells. However, these bore wells produce increasingly polluted and salinized water due to declining groundwater tables. Ahmedabad's CBF also shows high scores on drinking water consumption and solid waste collected, which is a result of Ahmedabad's low per capita water consumption and waste production. However, consumption varies as wealthy households are generally more waste- and waterintensive than poor households. The low BCI also implies that there are many improvement options in for example the city's wastewater treatment, solid waste treatment and climate adaptation activities.

\section{Water governance}

Table 2 provides an overview of GCF results for Ahmedabad. Overall, the results show that there is much room for improvement with respect to the four water challenges of water scarcity, flood risk, wastewater treatment and solid waste treatment. The governance capacity to address urban heat islands, however, is high and sets an example of how Ahmedabad may be able to address the other four challenges. One of the most remarkable results is that visionary agents (ind. 6.3) within the government use their authority (ind. 7.3) to set ambitious goals (ind. 5.1) for all five water-related challenges. However, insufficient statutory compliance (ind. 9.2) and the inadequate use of policy instruments (ind. 9.1) are limiting the implementation of these goals while monitoring (ind. 3.1) and policy evaluation (ind. 3.2) are insufficient to improve implementation. In general, the awareness, management ambition and financial viability (respectively conditions 1, 5 and 8 ) are in many cases encouraging the governance capacity. On the other hand, continuous learning, stakeholder engagement and implementing capacity (respectively conditions 3, 4 and 9) are often limiting the governance capacity needed to address Ahmedabad's water challenges. In particular, the development of implementing capacity can be considered a priority.
Most important governance issues to improve

\section{Useful knowledge and continuous learning}

The existence of reliable open information, monitoring schemes, policy evaluation and cross-stakeholder learning processes (respectively indicators 2.1, 2.2, 3.1, 3.2 and 3.3) are essential to build-up the necessary knowledge base and learning activities to address water challenges. The lack of these factors was found to have a limiting effect on Ahmedabad's water governance, a conclusion that is in line with the OECD's (2014) analysis of India's national water governance. The low score on condition 3 useful knowledge indicates Ahmedabad's limited availability, transparency and cohesion of reliable data. Available information is fragmented over different organisations and sources. Examples of inadequate information, monitoring and evaluation are found across four of the five water challenges: First, data on the declining groundwater table is said to be measured, but information is hardly accessible and often inaccurate. Secondly, there is limited data available on industrial effluent water quality because of insufficient monitoring. Thirdly, only the volumes of solid waste are registered. Consequently, there is no knowledge on the composition of the solid waste, which is valuable knowledge for future waste recovery and recycling. The lack of sufficient monitoring is not only a problem in itself, it also hampers the possibility for policy evaluation and learning. Overall, most stakeholders expressed the feeling that the linkage between policy and research is currently weak. Policies are rarely based on thorough research, a situation that leaves room for improvement.

\section{Stakeholder engagement}

Despite the growing effort to include stakeholders in policy development, the actual engagement of stakeholders is limited. Different forms of engagement are practiced. Open consultations via online feedback forms have been introduced where citizens can register their opinions and remarks. The Ahmedabad Municipal Corporation's Complaint Registration can be reached by phone, SMS and internet and has already registered more than one million complaints in 3 years. ${ }^{2,3}$ However, project-specific stakeholder consultation is characterised by closed, ad hoc engagements, whereby the stakeholder's influence on the result is rather unclear and limited. Often, only a limited number of stakeholders are invited, mostly academics or research institutes, that can support the municipality in

\footnotetext{
$\overline{2 \mathrm{http} / / / \mathrm{www} . a m c c r s . c o m / A M C P o r t a l / V i e w / C o m p l a i n t R e g i s t r a t i o n . a s p x ~}$ Accessed on 30-11-2016

${ }^{3} \mathrm{http} / / /$ www.dnaindia.com/ahmedabad/report-want-to-complain-to-amc-dial155303-1847434 Accessed on 30-11-2016
} 
Fig. 2 Results of the assessment using the City Blueprint

Framework (CBF) to measure water management performance of the city of Ahmedabad. The overall score, the Blue City Index $(\mathrm{BCI})$, is 3.13 points out of 10

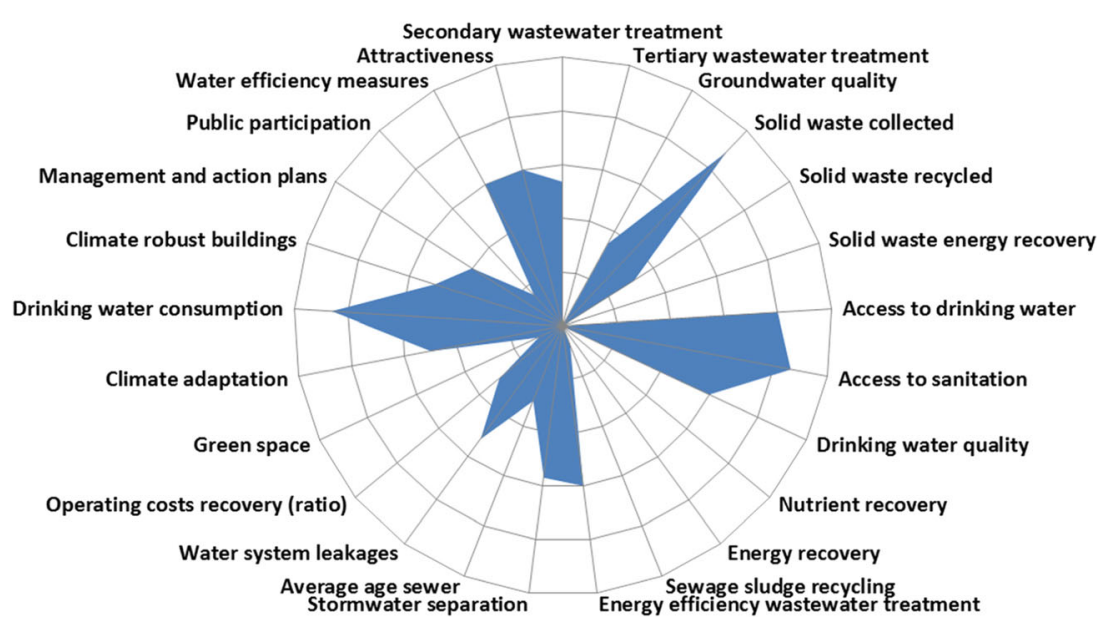

sewage treatment capacity. High levels of organic load confirm the discharge of untreated domestic sewage and industrial wastewater in the river (Prajapati 2014; Shah and Joshi 2015). Interviews with stakeholders showed that none of the interviewees could name recent penalised activities or sanctioned non-compliance regarding wastewater. On top of that are records about environmental compliance of wastewater treatment plants that are not accessible to the public.

Insufficient multi-level network potential (condition 7) is an important explanatory factor for the lack of implementing capacity. Stakeholders that should be working together are said to speak 'different languages', which is hampering vertical multi-level governance communication. Additionally, responsible agencies are short of expertise and manpower to implement and execute the policies and laws, laid down by policy makers. The lack of vertical communication, collaboration and mutual understanding is leading to abstract policies that are difficult to implement. Horizontally, mandates and tasks are overlapping or not sufficiently assigned, leading to multi-level governance gaps (OECD 2015; Koop and Van Leeuwen 2017) and low enforcement. There are too many agencies and organisations assigned with similar tasks that act more or less in isolation. Hence, in order to improve the implementing capacity, multi-level governance and policies should be better coordinated while the required high ambitions put emphasis on local capacity building.

\section{Addressing water governance: lessons from Ahmedabad's Heat Action Plan}

Four of the five water challenges show similar encouraging and limiting governance conditions. On the contrary, the governance capacity to address urban heat islands is generally encouraging. By using Ahmedabad's Heat Action Plan (HAP) as a best practice case, it is shown that the development of governance is feasible for the other water Sabarmati River is of low quality because of insufficient 
Table 2 Outcome of the Governance Capacity Framework (GCF) analysis of Ahmedabad per water-related challenge

\begin{tabular}{|c|c|c|c|c|c|c|c|}
\hline Dimension & Conditions & Indicators & $\begin{array}{l}\text { Water } \\
\text { scarcity }\end{array}$ & Flood risk & $\begin{array}{l}\text { Wastewater } \\
\text { treatment }\end{array}$ & $\begin{array}{l}\text { Solid waste } \\
\text { treatment }\end{array}$ & $\begin{array}{l}\text { Urban heat } \\
\text { islands }\end{array}$ \\
\hline \multirow[t]{9}{*}{ Knowing } & \multirow[t]{3}{*}{ 1. Awareness } & 1.1 Community knowledge & + & + & 0 & 0 & + \\
\hline & & 1.2 Local sense of urgency & - & + & - & - & + \\
\hline & & $\begin{array}{l}\text { 1.3 Behavioural } \\
\text { internalisation }\end{array}$ & - & 0 & 0 & 0 & + \\
\hline & \multirow[t]{3}{*}{ 2. Useful knowledge } & 2.1 Information availability & 0 & 0 & 0 & - & + \\
\hline & & 2.2 Information transparency & - & 0 & - & + & 0 \\
\hline & & 2.3 Knowledge cohesion & - & 0 & 0 & 0 & 0 \\
\hline & \multirow[t]{3}{*}{ 3. Continuous learning } & 3.1 Smart monitoring & - & - & 0 & - & + \\
\hline & & 3.2 Evaluation & - & - & - & - & + \\
\hline & & $\begin{array}{l}\text { 3.3 Cross-stakeholder } \\
\text { learning }\end{array}$ & 0 & 0 & - & 0 & 0 \\
\hline \multirow[t]{9}{*}{ Wanting } & \multirow[t]{3}{*}{$\begin{array}{l}\text { 4. Stakeholder engagement } \\
\text { process }\end{array}$} & $\begin{array}{l}\text { 4.1 Stakeholder } \\
\text { inclusiveness }\end{array}$ & - & 0 & - & 0 & + \\
\hline & & 4.2 Protection of core values & 0 & 0 & - & 0 & + \\
\hline & & $\begin{array}{l}4.3 \text { Progress and variety of } \\
\text { options }\end{array}$ & 0 & - & - & 0 & 0 \\
\hline & \multirow[t]{3}{*}{ 5. Management ambition } & $\begin{array}{l}\text { 5.1 Ambitious realistic } \\
\text { management }\end{array}$ & 0 & + & + & + & + \\
\hline & & 5.2 Discourse embedding & - & - & 0 & - & ++ \\
\hline & & 5.3 Management cohesion & 0 & 0 & 0 & 0 & 0 \\
\hline & \multirow[t]{3}{*}{ 6. Agents of change } & 6.1 Entrepreneurial agents & - & - & - & 0 & + \\
\hline & & 6.2 Collaborative agents & 0 & 0 & 0 & - & + \\
\hline & & 6.3 Visionary agents & 0 & - & + & 0 & + \\
\hline \multirow[t]{9}{*}{ Enabling } & \multirow{3}{*}{$\begin{array}{l}\text { 7. Multi-level network } \\
\text { potential }\end{array}$} & 7.1 Room to manoeuvre & 0 & 0 & - & 0 & 0 \\
\hline & & $\begin{array}{l}\text { 7.2 Clear division of } \\
\text { responsibilities }\end{array}$ & 0 & 0 & 0 & 0 & + \\
\hline & & 7.3 Authority & 0 & 0 & + & 0 & + \\
\hline & \multirow[t]{3}{*}{ 8. Financial viability } & 8.1 Affordability & 0 & 0 & + & 0 & + \\
\hline & & $\begin{array}{l}8.2 \text { Consumer willingness to } \\
\text { pay }\end{array}$ & + & + & 0 & 0 & + \\
\hline & & 8.3 Financial continuation & + & + & + & + & + \\
\hline & \multirow[t]{3}{*}{ 9. Implementing capacity } & 9.1 Policy instruments & - & - & - & 0 & 0 \\
\hline & & 9.2 Statutory compliance & - & - & - & - & + \\
\hline & & 9.3 Preparedness & - & + & - & - & ++ \\
\hline
\end{tabular}

Scores range from very encouraging $(++)$ to very limiting $(--)$ to the governance capacity

challenges as well, provided that all enabling governance conditions are pursued.

\section{Necessity of a Heat Action Plan}

Heat stress, especially in Ahmedabad's urban heat island, is very serious, especially in the pre-monsoon summer months, when temperatures reach $40-45{ }^{\circ} \mathrm{C}$ (Knowlton et al. 2014). In 2009, the Natural Resources Defence Council (NRDC), the Public Health Foundation of India (PHFI) and Ahmedabad's Municipal Corporation collaborated with a coalition of academics, health and environment groups, and local communities to develop a climate health project. NRDC is a USA-based non-profit environment advocacy group with a strong presence in India.
PHFI is an Indian public-private initiative that aims to enhance the capacity of public health professionals with several regional offices across India (Knowlton et al. 2014). During a heat wave in May 2010, the peak temperatures in Ahmedabad hit a height of $46.8{ }^{\circ} \mathrm{C}$, resulting in several cases of heat strokes. Researchers compared the number of deaths during the heat wave to reference periods in the years before. They found that during the 2010 heat wave, an excess of 1344 additional deaths was reported, an increase of $43.1 \%$ compared to the reference periods in previous years (Shah et al. 2014). The team recognised that Ahmedabad needed a plan to protect local communities. The Heat Adaptation Plan (HAP) was launched in 2014; the most recent version contains four main points (Shah et al. 2014): 
1. Building public awareness and community outreach: All forms of (social)media are used to create awareness and educate people on heat waves and its impacts. Educational programmes are set up in school and vulnerable communities are being reached via grass-root level organisations

2. Initiating an early warning system and inter-agency coordination: Heat wave alerts are provided based on weather forecasts. As soon as an alert is given, the message is being dispersed via all media outlets and key agencies are notified to coordinate relevant tasks

3. Capacity building of health care professionals: Workshops and education for healthcare workers are organised in order to identify and address heat-related health conditions

4. Reducing heat exposure and promoting adaptive measures: More safe public drinking water facilities are provided in order to ensure sufficient water supply for the city and its vulnerable communities. Working hours are changed to avoid physical outdoor labour during peak heat hours.

\section{Heat Action Plan impact}

Heat alerts were finding their way to the population and behavioural changes were observed by the HAP coalition during the first heat wave after the introduction and implementation of the HAP. Confirming a causal relation between the HAP and behaviour change leading to heat risk adaptation is difficult in a large city like Ahmedabad. However, a decline in heatstroke cases and deaths was reported in 2014 in comparison to 2010, while temperatures reached similar heights as in 2010 (Dutta 2016). During the 2016 June heat wave, the hottest month within a 100-year record, the number of heatrelated deaths reported was lower than that of the 2010 heat wave, whereas the population had increased considerably. ${ }^{4}$ These preliminary results may point to a successful impact of the HAP on heat-related health issues in Ahmedabad.

\section{Successful governance through inclusion of governance conditions}

The HAP can be regarded as a success because of the integration and development of essential governance conditions. First of all, the action plan is based on robust research and empirical knowledge, creating awareness amongst the public, healthcare workers and governmental agencies and opens up possibilities for policy evaluation and improvement. Secondly, the initiating coalition consisted of a broad group

\footnotetext{
$\overline{4}$ http://www.thehindu.com/sci-tech/health/how-ahmedabad-beat-the-heat/ article17759591.ece Accessed on 13-03-2018
}

of stakeholders on the topic of heat stress, enabling a strong inclusive support base for policies. The group was able to build trust, confidence and the political will to act. Ahmedabad's Municipal Corporation showed ambitious managerial leadership by bringing in a broad coalition of actors to tackle the problem of urban heat stress. Thirdly, the involved actors were trained through simulations ahead of the heat season. All stakeholders were therefore sufficiently aware of their own and other's responsibilities, resulting in adequate multilevel network potential. The coalition is constantly working with officials and involved actors to evaluate and assess the effectiveness of the HAP. Continuous monitoring and evaluation of practices allow for learning and necessary adjustments throughout the year (Shah et al. 2014). From these evaluations, the drive for a Green Action Plan was born in 2015. This plan aims to plant thousands of trees in the coming years, providing cooling shade to tackle the effects of the urban heat island. ${ }^{5}$ Urban heat risk is being addressed by the development of the most limiting governance conditions in Ahmedabad: continuous learning, stakeholder engagement, multi-level network potential and implementing capacity (conditions 3, 4, 7 and 9 in Table 2).

\section{Discussion}

This study has found that Ahmedabad's capacity to govern water challenges is predominantly limited by insufficient knowledge, learning, stakeholder engagement and limited capacity to implement policies and practices. First, the linkage between policy and research is weak. This is amplified by a lack of monitoring which results in limited availability of reliable data. Subsequently, the lack of data and knowledge hampers the city's ability to learn and continuously improve existing practices. Secondly, there is little coordination between stakeholders in the urban water network. Inadequate horizontal inclusion of stakeholders in the policy process results in insufficient support for new plans, whereas too little vertical coordination leads to policies that lack feasibility when implemented in the lower levels of government. Thirdly, the implementation of new policies and projects proves to be a difficult step. Causes can be found in limited vertical and horizontal collaboration between stakeholders in the urban water network. An unclear and overlapping division of responsibilities hampers the implementation leading to non-compliance with environmental legislation, issues that have been observed throughout India and in other countries too (OECD 2015).

Given the rapid urban growth, water becomes the critical factor to support or limit the urbanisation process in India

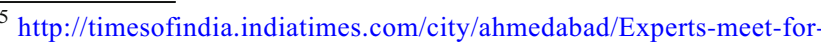
preparing-Green-Action-Plan-for-Ahmedabad/articleshow/52426421.cms
} 
(Roy 2013). Inadequate inclusion of stakeholders in the policy process has been widely reported in large Indian cities. In particular, with respect to access to clean drinking water, inequalities between sexes, between formal and informal settlements and different communities have been found (e.g. Roy 2013; Desai 2018; Cullet 2009). Kumar et al.'s (2009) conclusions, based on a study of 59 Indian cities, are in line with the results of Ahmedabad. They conclude that insufficient manpower, implementation and financial resources limit adequate solid waste collection and treatment. In particular, the need for strengthening existing monitoring mechanisms was identified as a critical factor (Kumar et al. 2009). Based on a review of national and state water policies in India, Katyaini and Barua (2016) found that only a few water policies were based on the latest scientific research on water scarcity, water efficiency and climate change. In fact, many water-scarce states have not implemented state-specific water policies. A top-down approach characterised by poor communication, a lack of trust and a stakeholder participation process that is often restricted to policy implementation has been opted to inhibit meaningful science-policy interaction (Katyaini and Barua 2016; Patra and Kantariya 2014; Cullet 2009). Similar factors can be identified to explain the weak linkage between research and policy in Ahmedabad. Climate change, population growth and urbanisation will only amplify the current challenges and increase the necessity to strengthen the governance capacity in urban India. Although this understanding of Ahmedabad's governance makes only one case, it is a city representative of urban Indian governance. It can therefore be argued that other large cities in India face similar governance challenges (MGI 2010; OECD 2014). The demand for water resources is expected to rise by over $70 \%$ by 2025 , inducing a gap between supply and demand (OECD 2014). Well-managed water resources and adequate water supply are vital to ensure sustainable economic growth and further alleviation of poverty. To some extent, these lessons could be useful for other cities in India. They also point to the need for further research into the governance capacity of cities in other regions in the Global South that also face rapid urbanisation, diminishing freshwater supplies and extreme weather.

In order to improve India's urban water governance capacity, the focus should be on capacity building to address the most limiting governance conditions. Because there are many causes that lead to complexity, uncertainty and sometimes disagreement in governance, there is no single best approach to improve the urban governance capacity (Koop et al. 2017). An integrated approach is required that enables cities to gain this governance capacity and find long-term flexible solutions which can adapt and anticipate emerging barriers and changing situations (OECD 2015; Koop and Van Leeuwen 2017). When used well, a stakeholder network can boost great opportunities to assess specific issues, to provide recommendations for stakeholder groups and to shape learning alliances to speed up the necessary transformations in cities (Koop et al. 2017). Through the case study of Ahmedabad, we have shown that the CBA can be fairly well applied in Indian cities. However, we found that the five water challenges of the GCF - water scarcity, flood risk, wastewater treatment, solid waste treatment and urban heat islands - did not entirely cover the main water-related issues in Ahmedabad. In particular, our study failed to include the issue of water-borne diseases which is very relevant in Ahmedabad. Hence, the formulation of water-related challenges should be reconsidered to better resemble the main issues in the Global South. The Sustainable Development Goals (SDGs) in particular SDG6 Ensure access to water and sanitation for all; and SDG11 Making cities inclusive, safe, resilient and sustainable can provide important direction. Only in this way, the CBA can better suit the relevant issues that cities experience in the Global South.

In the 'Introduction' section, we raised the question of whether and to what extent the CBA might fulfil the function of a boundary object that has the potential to lead to more productive science-policy interactions in the Indian context. We argue that the application of the approach has shown three strengths and one weakness. A first strength is that the approach helped to engage different water governance actors. The main stakeholders of water governance in Ahmedabad were interviewed and were, in that sense, incorporated in the process. Inherent in the approach's design is that opinions, facts and background information of all relevant stakeholders are collected. This makes it a useful tool for the collection and recognition of stakeholder perspectives. The process lacked the time and resources to actually bring stakeholders together, though. Second, the CBA is a standardised and therewith reproducible approach. It functioned as a joint fact-finding process, enabling an agreed-upon analysis of the city's achievements, as well as an identification of the most urgent governance challenges. This provides for a good starting point for future joint efforts in enhancing water governance capacity in Ahmedabad. Third, the approach provided an outside perspective since the process was facilitated and coordinated by a researcher from abroad. Applying the approach in Ahmedabad was in essence a short but useful intervention. For the involved stakeholders, following the approach helped to gain much knowledge and insights with limited time investments. It also provided concrete opportunities to share knowledge and experiences with other cities assessed by the CBA that may lead to higher efficiencies and inspiration, and allows for an empirical-based accumulation of knowledge and learning within the scientific community.

Because of these strengths, the CBA can be seen as a boundary object (Star and Griesemer 1989), partly addressing several success conditions as they have been documented for joint knowledge production processes in a Western context (Hegger et al. 2012). In essence, the CBA provides a resource for joint knowledge production that helps to engage actors and 
ensure that their opinions, facts and background information are included in the assessment. However, a downside of the approach is that it is temporary in nature. The CBA in itself does not automatically bring actors together, let alone induce or stimulate sustained cooperation between these actors, while this is an important next step in participatory knowledge production processes, as suggested by Armitage et al. (2011) in a North American context. Therefore, the CBA can only achieve its objectives if it is incorporated in a long-term and broader stakeholder interaction programme. The sustained application of the approach is only possible if sufficient resources are present. The work in Ahmedabad has been financed by KWR Watercycle Research Institute and Wetskills. It is still an open question if the necessary resources are present to further develop and apply the City Blueprint Approach and to sustain innovation processes that were started in Ahmedabad. We hope that the memorandum of understanding between the Republic of India and the European Union on water cooperation signed in 2016 will facilitate the necessary exchange of expertise to address the challenges of water, waste and climate change in cities in India and beyond.

\section{Conclusion}

Water 'crises' are largely a result of mismanagement, with strong public governance implications. Connecting water science and policy is key in developing the necessary capacity to govern urban water challenges. To do so, cities first need to develop a common understanding of what their limiting and enabling conditions are before meaningful science-policy interaction can take shape. In this paper, a cohesive, comprehensive and applicable assessment of water management and governance in Ahmedabad was used to provide an integrated empirical-based understanding of the most important enabling conditions that determine the city's ability to govern their water challenges. In Ahmedabad, it is found that the main governance conditions that need to be improved are continuous learning, stakeholder engagement process and implementing capacity. The example of Ahmedabad's Heat Action Plan showed that it is possible for cities to overcome limiting governance conditions and implement successful policies. Based on this understanding of the most enabling and limiting governance conditions, we can conclude that the role and opportunities provided by the application of the City Blueprint Approach provide a short but useful intervention that can enhance science-policy interactions and capacity building in Ahmedabad. The approach allows a city to quickly understand how advanced it is in sustainable water management and governance and to compare its status with other cities. However, in order to facilitate a long-term joint knowledge production process, the approach needs to be incorporated in a broader stakeholder interaction programme.
The City Blueprint Approach facilitates the first step in improving water governance in two main ways. The inclusive process in which governance conditions are assessed requires a critical reflection of involved stakeholders on the current governance practices. The methodology subsequently induces learning with the involved stakeholders. More importantly, the approach provides insights in the most limiting governance conditions that provide important direction towards the most feasible solution pathways. The method's standardised, integrated and systematic assessments of water governance may also provide valuable insight into a city's strengths and weaknesses and the extent to which these can be influenced through (governance) interventions. All this is supported by definitive concepts and clearly described indicators that are publicly accessible. The methodology allows for standardisation and reproducibility of results. A weakness of this standardisation is its applicability to countries in the Global South, which is for instance shown by the blind spot for water-borne diseases. Therefore, the CBA's effectiveness requires a redefinition of the main water challenges that are subjected to the governance analysis. At the same time, the methodology is able to detect good practices that may be used as positive examples for the cities concerned. The application of the CBA to the city of Ahmedabad was done in an interactive way, through what can be considered as a joint knowledge production process (Hegger et al. 2012; Raadgever et al. 2012). This is beneficial to the usefulness of the findings and acceptance of concrete action perspectives such as the Heat Action Plan of Ahmedabad.

Acknowledgements We would like to thank all who participated and contributed to this study. Especially, we thank the Centre for Environment Education in Ahmedabad for hosting our research activities during the stay in Ahmedabad. We thank the many interviewees and organisations that have provided us with valuable information: Ahmedabad's Municipal Corporation, Mahila Housing SEWA Trust (MHT), Gujarat University, CEPT University, Times of India, Public Health Foundation of India (PHFI), Paryavaran Mitra, Gujarat Water Supply and Sewerage Board, Gujarat Pollution Control Board, Urban Management Centre Group, VIKSAT, and the Ahmedabad Water Walk Initiative. The City Blueprint Approach has been developed at KWR Watercycle Research Institute in the context of Watershare (http://www. watershare.eu). The City Blueprint Action Group is part of the European Innovation Partnership on Water of the European Commission (http://www.eip-water.eu/City_Blueprints).

Funding information The European Commission is acknowledged for Funding POWER in H2020-Water under grant agreement no. 687809.

Open Access This article is distributed under the terms of the Creative Commons Attribution 4.0 International License (http:// creativecommons.org/licenses/by/4.0/), which permits unrestricted use, distribution, and reproduction in any medium, provided you give appropriate credit to the original author(s) and the source, provide a link to the Creative Commons license, and indicate if changes were made. 


\section{References}

Armitage D, Berkes F, Dale A, Kocho-Schellenberg E, Patton E (2011) Co-management and the co-production of knowledge: learning to adapt in Canada's Arctic. Glob Environ Chang 21:995-1004. https://doi.org/10.1016/j.gloenvcha.2011.04.006.

Biesbroek GR, Klostermann JEM, Termeer CJAM, Kabat P (2013) On the nature of barriers to climate change adaptation. Reg Environ Chang 13:1119-1129. https://doi.org/10.1007/s10113-013-0421-y

Cairney P (2013) Standing on the shoulders of giants: how do we combine the insights of multiple theories in public policy studies? Policy Stud J 41:1-21. https://doi.org/10.1111/psj.12000

Cullet P (2009) From water sector reforms to law and policy reforms. Water law, poverty and development: Water Sector Reforms in India. Oxford University Press, New Delhi, pp 63-103

Desai R (2018) Urban planning, water provisioning and infrastructural violence at public housing resettlement sites in Ahmedabad, India. Water Altern 11(1):86-105. http://www.water-alternatives.org/ index.php/alldoc/articles/vol11/v11issue1/421-a11-1-5/file

DFID (2003) Department for International Development: tools for development. A handbook for those engaged in development activities

Dutta P (2016) Climate change: addressing heat-health vulnerability in rapidly urbanising regions of Western India. $4^{\text {th }}$ International Climate Change Adaptation Conference. http://edepot.wur.nl/ 381666

Eisenack K, Moser SC, Hoffmann E, Klein RJT, Oberlack C, Pechan A, Rotter M, Termeer CJAM (2014) Explaining and overcoming barriers to climate change adaptation. Nat Clim Chang 4:867-872. https://doi.org/10.1038/nclimate2350

European Commission (2017a) City blueprint action group. Indicators of the trends and pressures framework https:/www.eip-water.eu/sites/ default/files/Indicators $\% 20$ of $\% 20$ the $\% 20$ Trends $\% 20$ and $\%$ 20Pressures $\% 20$ Framework\%20\%28Sept $\% 202017 \% 29$.pdf [2610-2017]

European Commission (2017b) City blueprint action group. Indicators of the city blueprint framework https://www.eip-water.eu/sites/default/ files/Indicators $\% 20$ of $\% 20$ the $\% 20$ City $\% 20 \mathrm{Blueprint} \%$ 20Framework 0.pdf [26-10-2017]

European Commission (2017c) City blueprint action group. Indicators of the water Governance Capacity Framework https://www.eip-water. $\mathrm{eu} / \mathrm{sites} / \mathrm{default} / \mathrm{files} /$ Indicators $\% 20$ of $\% 20$ the $\% 20$ Water $\%$ 20Governance\%20Capacity\%20Framework_0.pdf [26-10-2017]

European Commission (2017d) European Innovation Partnership on Water. City Blueprint action group. http://www.eip-water.eu/City_ Blueprints

Feingold D, Koop S, Van Leeuwen K (2017) The city blueprint approach: urban water management and governance in cities in the U.S. Environ Manag. https://doi.org/10.1007/s00267-017-0952-y

Gawlik B, Easton P, Elelman, R, Koop S, Van Leeuwen K (2017) The European urban water atlas, Joint Research Centre of the European Commission, Brussels

Gupte PR (2011) Ground Water Scenario in major cities in India. Central Gound Water Board, Government of India

Hegger D, Lamers M, Van Zeijl-Rozema A, Dieperink C (2012) Conceptualising joint knowledge production in regional climate change adaptation projects: success conditions and levers for action. Environ Sci Pol 18:52-65. https://doi.org/10.1016/j. envsci.2012.01.002

Janaagraha Centre for Citizenship and Democracy (2015) Annual survey of India's city-systems (ASICS). Bengaluru

Katyaini S, Barua A (2016) Water policy at the science-policy interface: challenges and opportunities for India. Water Policy 18:288-303. https://doi.org/10.2166/wp.2015.086.

Knowlton K, Kulkarni SP, Azhar GS, Mavalankar D, Jaiswal A, Connolly M, Nori-Sarma A, Rajiva A, Dutta P, Deol B, Sanchez
L, Khosla R, Webster PJ, Toma VE, Sheffield P, Hess JJ, Ahmedabad Heat and Climate Study Group (2014) Development and implementation of South Asia's first heat-health action plan in Ahmedabad (Gujarat, India). Int J Environ Res Public Health 11: 3473-3492. https://doi.org/10.3390/ijerph110403473

Koop SHA, Van Leeuwen CJ (2015a) Assessment of the sustainability of water resources management: a critical review of the city blueprint approach. Water Resour Manag 29:5649-5670. https://doi.org/10. 1007/s11269-015-1139-z

Koop SHA, Van Leeuwen CJ (2015b) Application of the improved city blueprint framework in 45 municipalities and regions. Water Resour Manag 29:4629-4647. https://doi.org/10.1007/s11269-015-1079-7

Koop SHA, Van Leeuwen CJ (2017) The challenges of water, waste and climate change in cities. Environ Dev Sustain 19:385-418. https:// doi.org/10.1007/s10668-016-9760-4

Koop SHA, Koetsier L, Van Doornhof A, Reinstra O, Van Leeuwen CJ, Brouwer S, Dieperink C, Driessen P (2017) Assessing governance capacity of cities to address challenges of water, waste and climate change. Water Resour Manag 31:3427-3443. https://doi.org/10. 1007/s11269-017-1677-7.

Kumar S, Bhattacharyya JK, Vaidya AN, Chakrabarti T, Devotta S, Akolkar AB (2009) Assessment of the status of municipal solid waste management in metro cities, statecapitals, class I cities, and class II towns in India: an insight. Waste Manag 29:883-895. https:// doi.org/10.1016/j.wasman.2008.04.011

Kumar MD, Bassi N, Venkatachalam L, Sivamohan MVK, Niranjan V (2012) Capacity building in water resources sector of India. Occas Pap 5-0112. Institute of Resources Analysis \& Policy, Hyderabad

Lange P, Driessen PPJ, Sauer A, Bornemann B, Burger P (2013) Governing towards sustainability-conceptualizing modes of governance. J Environ Policy Plan 15:403-425. https://doi.org/10.1080/ 1523908X.2013.769414

Maheshwari R (2016) Impact of Industrial Estates on Water Resources. International Journal of Environ Sci and Dev 7-12. http://www. ijesd.org/vol7/907-C0001.pdf

McGranahan G, Jacobi P, Songsor J, Surjadi C, Kjellen M (2001) The citizens at risk: from urban sanitation to sustainable cities. Earthscan, London

MGI (2010) India's urban awakening: building inclusive cities, sustaining economic growth. McKinsey Global Institute, Delhi

OECD (2014) Water: improving water security in India. India Policy Brief. Organization for Economic Cooperation and Development, Paris

OECD (2015) OECD principles on water governance. Organisation for Economic Cooperation and Development, Paris, Paris

Ostrom E (2009) A general framework for analyzing sustainability of social-ecological systems. Science 24:419-422. https://doi.org/10. $1126 /$ science. 1172133

Pahl-Wostl C (2009) A conceptual framework for analysing adaptive capacity and multi-level learning processes in resource governance regimes. Glob Environ Chang 19:354-365. https://doi.org/10.1016/ j.gloenvcha.2009.06.001

Patra J, Kantariya K (2014) Science-policy interface for disaster risk management in India: toward an enabling environment. Curr Sci 107:39-45. http://www.currentscience.ac.in/Volumes/107/01/0039. pdf

Plummer R, Crona B, Armitage DR, Olsson P, Tengo M, Yudina O (2012) Adaptive comanagement: a systematic review and analysis. Ecol Soc 17(3):11. https://doi.org/10.5751/ES-04952-170311

Prajapati K (2014) Ecological evaluation of water of Sabarmati, Ahmedabad. Asian J Animal Sci 9(1):38-42. http://www. researchjournal.co.in/upload/assignments/9_38-42.pdf

Raadgever GT, Mostert E, van de Giesen NC (2012) Learning from collaborative research in water management practice. Water Resour Manag 26:3251-3266. https://doi.org/10.1007/s11269-0120070-9 
Reed MS, Graves A, Dandy N, Posthumus H, Hubacek K, Morris J, Prell C, Quinn CH, Stringer LC (2009) Who's in and why? A typology of stakeholder analysis methods for natural resource management. J Environ Manag 90:1933-1949. https://doi.org/10.1016/j.jenvman. 2009.01.001

Roy D (2013) Negotiating marginalities: right to water in Delhi. Urban Water J 10(2):97-104. https://doi.org/10.1080/1573062X.2012. 709254

Schreurs E, Koop S, Van Leeuwen K (2018) Application of the city blueprint approach to assess the challenges of water management and governance in Quito (Ecuador). Environ Dev Sustain 20:509525. https://doi.org/10.1007/s10668-017-9916-x

Shah KA, Joshi GS (2015) Evaluation of water quality index for River Sabarmati, Gujarat, India. Appl Water Sci 7:1-10. https://doi.org/10. 1007/s13201-015-0318-7

Shah T, Mavalankar D, Gulrez Shah Azhar G, Connolly M, Jaiswal A (2014) Addressing heat-related health risks in urban India: Ahmedabad's heat action plan. Climate \& Development Knowledge Network. https://www.nrdc.org/sites/default/files/ ahmedabad-cdkn-inside-story.pdf

Star SL, Griesemer JR (1989) 'Translations' and boundary objects: amateurs and professionals in Berkeley's Museum of Vertebrate Zoology. 1907-39. Soc Stud Sci 19:387-420. https://doi.org/10. 1177/030631289019003001

Surinaidu L, Gurunadha Rao VVS, Mahesh J, Prasad PR, Tamma Rao G, Sarma VS (2015) Assessment of possibility of saltwater intrusion in the central Godavari delta region, Southern India. Reg Environ Chang 15:907-918. https://doi.org/10.1007/s10113-014-0678-9

UN Habitat (2016) Urbanization and development: emerging futures

Van Enst WI, Driessen PPJ, Runhaar HAC (2014) Towards productive science-policy interfaces: a research agenda. JEAPM 16:1450007. https://doi.org/10.1142/S1464333214500070
Van Kersbergen KV, Van Waarden FV (2004) Governance' as a bridge between disciplines: cross-disciplinary inspiration regarding shifts in governance and problems of governability, accountability and legitimacy. EJPR 43:143-171. https://doi.org/10.1111/j.1475-6765. 2004.00149.x

Van Leeuwen CJ (2017) Water governance and the quality of water services in the city of Melbourne. Urban Water J 14:247-254. https:// doi.org/10.1080/1573062X.2015.1086008

Van Leeuwen CJ, Bertram NP (2013) Baseline assessment and best practices in urban water cycle services in the city of Hamburg. Bluefacts 2013:10-16. https://doi.org/10.1007/s11269-013-0462-5

Van Leeuwen CJ, Sjerps RMA (2015) The city blueprint of Amsterdam. An assessment of integrated water resources management in the capital of the Netherlands. Water Sci Technol 15:404-410. https:// doi.org/10.2166/ws.2014.127

Van Leeuwen CJ, Sjerps RMA (2016) Istanbul: the challenges of integrated water resources management in Europa's megacity. Environ Dev Sustain 18:1-17. https://doi.org/10.1007/s10668-015-9636-z

Van Leeuwen CJ, Frijns J, van Wezel A, van de Ven FHM (2012) City blueprints: 24 indicators to assess the sustainability of the urban water cycle. Water Resour Manag 26:2177-2197. https://doi.org/ 10.1007/s11269-012-0009-1

Van Leeuwen CJ, Dan NP, Dieperink C (2016) The challenges of water governance in Ho Chi Minh City. Integr Environ Assess Manag 12: 345-352. https://doi.org/10.1002/ieam.1664

Vinke K, Martin MA, Adams S, Baarsch F, Bondeau A, Coumou D, Donner RV, Menon A, Perrette M, Rehfeld K, Robinson A, Rocha M, Schaeffer M, Schwan S, Serdeczny O, Svirejeva-Hopkins A (2016) Climatic risks and impacts in South Asia: extremes of water scarcity and excess. Reg Environ Chang 17:1-15. https://doi.org/10. 1007/s10113-015-0924-9.

Watershare (2017) Applying global expertise to local water challenges. https://www.watershare.eu/ 